\title{
Syndrome of inappropriate antidiuresis in prostate adenocarcinoma with neuroendocrine differentiation: a case report and literature review
}

\author{
Ilaria Fiordoliva', Giulia Marcantognini ${ }^{1}$, Silvia Rinaldi ${ }^{1}$, Alessia Cimadamore ${ }^{2}$, Rodolfo Montironi ${ }^{2}$, \\ Rossana Berardi ${ }^{1}$
}

${ }^{1}$ Medical Oncology, Università Politecnica delle Marche, Ospedali Riuniti Umberto I-GM Lancisi-G Salesi, Via Conca 71, Ancona 60126, Italy.

${ }^{2}$ Section of Pathological Anatomy, Università Politecnica delle Marche, School of Medicine, Ospedali Riuniti Umberto I-GM Lancisi-G Salesi, Via Conca 71, Ancona 60126, Italy.

Correspondence to: Rossana Berardi, Medical Oncology, Università Politecnica delle Marche, Ospedali Riuniti Umberto I-GM Lancisi- G Salesi, Via Conca 71, Ancona 60126, Italy. E-mail: r.berardi@univpm.it

How to cite this article: Prof. Berardi R. Syndrome of inappropriate antidiuresis in prostate adenocarcinoma with neuroendocrine differentiation: a case report and literature review. J Cancer Metastasis Treat 2019;5:59. DOI:10.20517/2394-4722.2019.23

Received: 12 Mar 2019 First Decision: 11 Apr 2019 Revised: 20 Apr 2019 Accepted: 27 Jun 2019 Published: 30 Jul 2019

Science Editor: Chun Hei Antonio Cheung Copy Editor: Cai-Hong Wang Production Editor: Jing Yu

\begin{abstract}
Syndrome of inappropriate antidiuresis (SIAD) is a common paraneoplastic syndrome commonly associated with thoracic malignancies, gastrointestinal cancers and kidney tumors. It is defined as hyponatremia in euvolemic patients, often due to abnormal secretion of antidiuretic hormone by tumor cells. Tolvaptan, a vasopressin-2receptor antagonist, is currently recommended for patients affected by SIAD with mild or moderate symptoms. Among patients with prostatic cancer, SIAD represents a rare condition but it is frequently associated with poorly differentiated adenocarcinoma or pure small-cell carcinoma histotype. We report a case of SIAD appeared at disease progression in a 60-year-old male patient with acinar adenocarcinoma with neuroendocrine differentiation together with a literature review.
\end{abstract}

Keywords: Hyponatremia, prostate cancer, syndrome of inappropriate antidiuresis, neuroendocrine differentiation

\section{INTRODUCTION}

Prostate cancer is the most common non-cutaneous cancer in Western men, with estimated $1,600,000$ cases annually ${ }^{[1]}$. The recent World Health Organization (WHO) 2016 classification

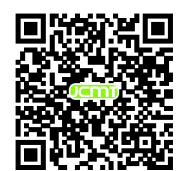


of neuroendocrine (NE) tumors of prostatic adenocarcinoma (PAC) includes the following four categories: Adenocarcinoma with neuroendocrine differentiation, Well-differentiated NE tumor (carcinoid tumor), Small cell NE carcinoma and Large cell NE carcinoma. Gleason score and grade group are the standard approach to histologic grading of PAC, but not for the NE components, and it is an important independent prognostic factor ${ }^{[2,3]}$. Clinical presentation and prognosis usually depend on local infiltration and metastatic spread. Paraneoplastic syndromes including syndrome of inappropriate antidiuresis (SIAD) are rare, mostly in poorly differentiated PAC, frequently with $\mathrm{NE}$ features ${ }^{[4]}$. SIAD is commonly associated with small cell lung cancer (SCLC), non-small cell lung cancer (NSCLC), gastrointestinal cancers, kidney cancers and mesothelioma ${ }^{[5]}$. In the last few years, several international and national guidelines have been published in order to improve clinical managing of this electrolyte disorder ${ }^{[6]}$. Oral tolvaptan, a vasopressin-2-receptor antagonist, has been approved by FDA and EMA for treatment of euvolemic hyponatremia due to SIAD with mild or moderate symptoms. Vaptans demonstrated to improve serum sodium concentration in patients with SIAD but there are still few data about their possible effect on survival of cancer patients ${ }^{[7]}$.

\section{CASE REPORT}

A 60-year-old male with PAC and abdominal lymph nodes and axial bone metastasis came to our Department. An informed consent to procedures and therapy was obtained from the patient. At first observation, the patient was in good clinical condition (Performance status according to Eastern Cooperative Oncology Group-ECOG-PS = 0) and he did not present significant comorbidities other than well-controlled arterial hypertension.

PAC diagnosis occurred in June 2014 when, after onset of urinary frequency and dysuria, patient underwent prostate biopsies. Histological examination reported prostatic acinar adenocarcinoma Gleason score $5+4=9$ (grade group 5, with NE differentiation $=5 \%$ ) [Figure 1]. PSA was $22 \mathrm{ng} / \mathrm{mL}$.

After diagnosis, a CT scan showed left iliac chain, para-aortic and inguinal bilateral lymphadenomegalies and osteoblastic metastasis to lumbar spin, multiple ribs and hip with no fracture risk. A bone scintigraphy confirmed bone involvement [Figure 2]. Laboratory values did not show clinically significant abnormalities.

In August 2014 the patient started complete androgen deprivation therapy with oral Bicalutamide $50 \mathrm{mg}$ daily along with intramuscular Leuprorelin $11.25 \mathrm{mg} / \mathrm{mL}$ quarterly. Denosumab $120 \mathrm{mg}$ monthly was started to prevent skeletal events. Serum PSA showed initial complete biochemical response (0.3 ng/mL). In November 2014 PSA raised to $10 \mathrm{ng} / \mathrm{mL}$. The patient presented with clinical worsening including increased urinary frequency and dysuria. Considering biochemical and clinical progression, Bicalutamide was stopped and first-line chemotherapy with Docetaxel $75 \mathrm{mg} / \mathrm{m}^{2}$ intravenously every three weeks was started. The patient underwent five cycles of chemotherapy until May 2015, continuing Denosumab and Leuprorelin. PSA decreased to $8.2 \mathrm{ng} / \mathrm{mL}$, with limited clinical benefit. After multidisciplinary evaluation, the patient was considered eligible for radiotherapy on the prostatic region. This treatment was performed between May 2015 and July 2015 (total dose: 5400 cGy).

After radiation therapy, PSA raised to $17.4 \mathrm{ng} / \mathrm{mL}$ and the patient was referred to our department for dorsal and abdominal pain. A total-body CT scan performed in August 2015 showed disease progression, including rectal thickening, multiple liver metastasis, peritoneal carcinosis and increase of abdominal and pelvic lymphadenomegalies. CT also showed disseminate osteoblastic metastasis [Figure 3]. 

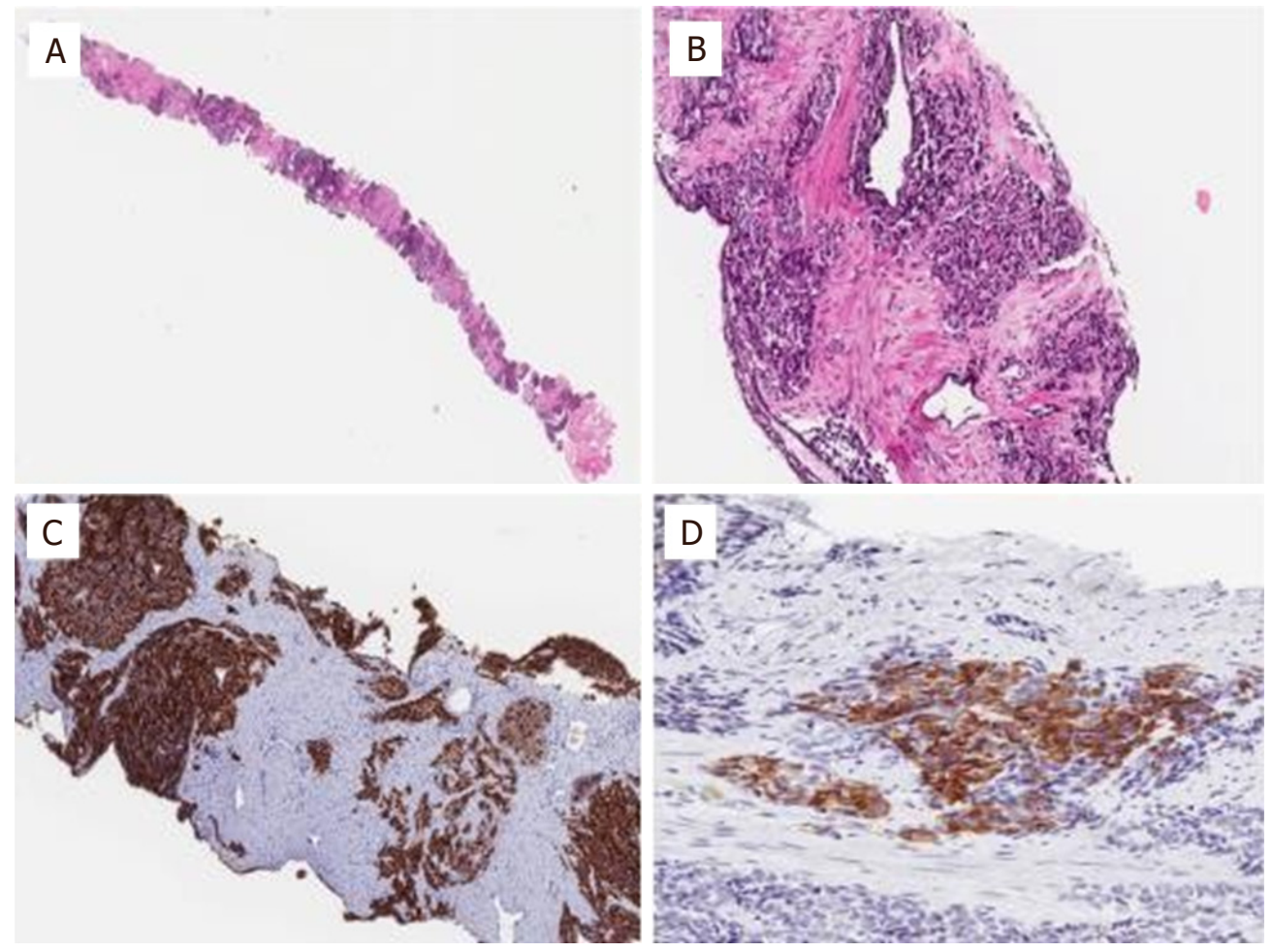

Figure 1. A: Prostate biopsy extensively involved by acinar adenocarcinoma with NE differentiation (5\%) at low magnification (hematoxylin and eosin-H\&E); B: prostate biopsy with solid area of adenocarcinoma at high magnification (H\&E); C: prostate biopsy with diffuse positivity for prostate specific membrane antigen (PSMA, immunohistochemistry); D: prostate biopsy with focal positivity for synaptophysin (immunohistochemistry)
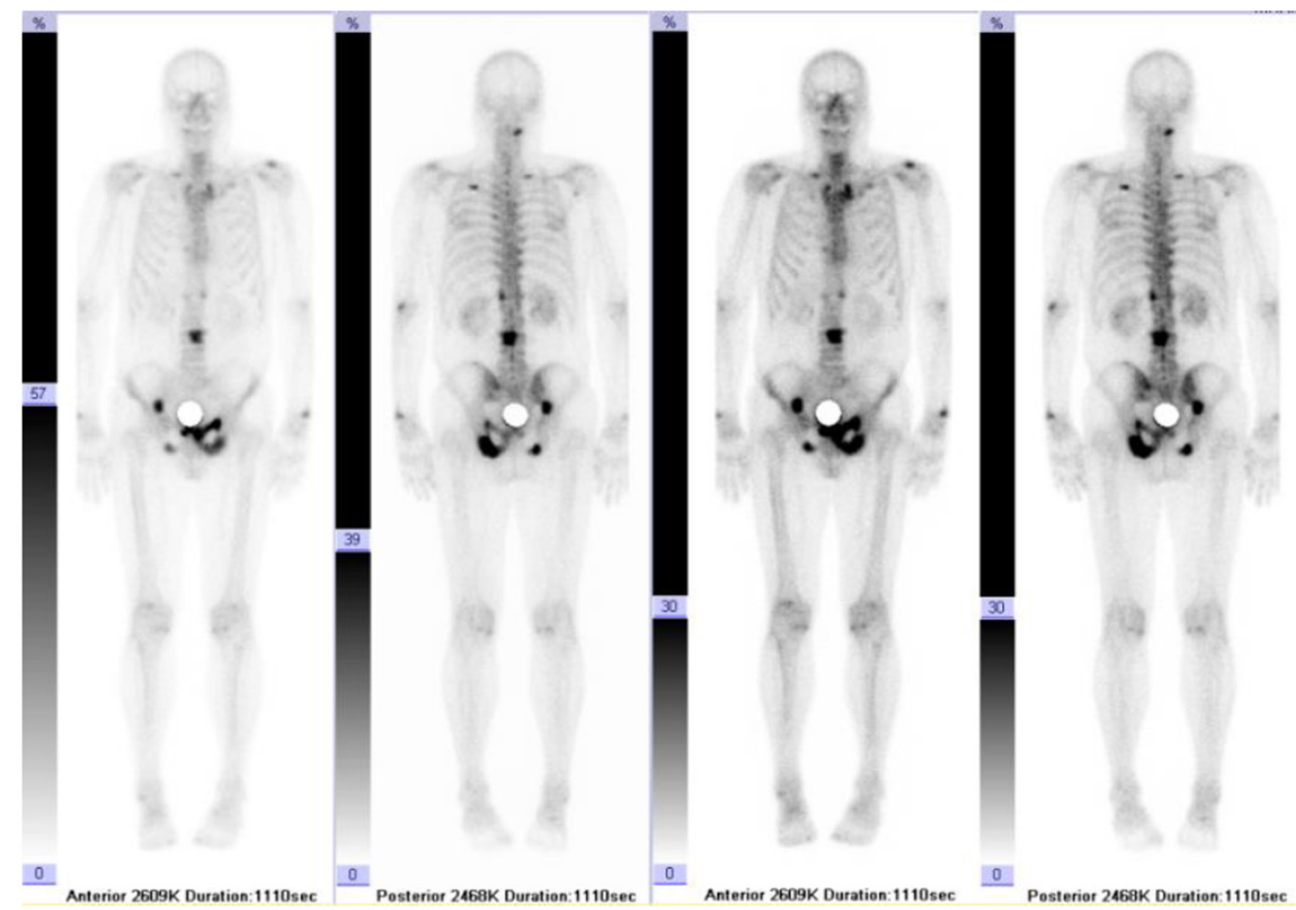

Figure 2. Bone scintigraphy confirming skeletal involvement 


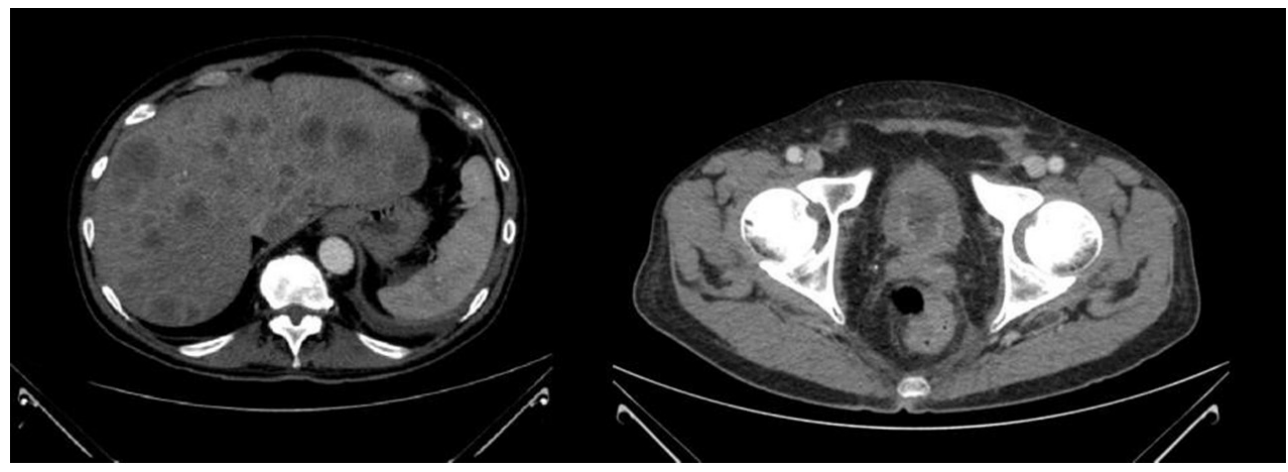

Figure 3. CT scan showing liver metastatization and rectal thickening
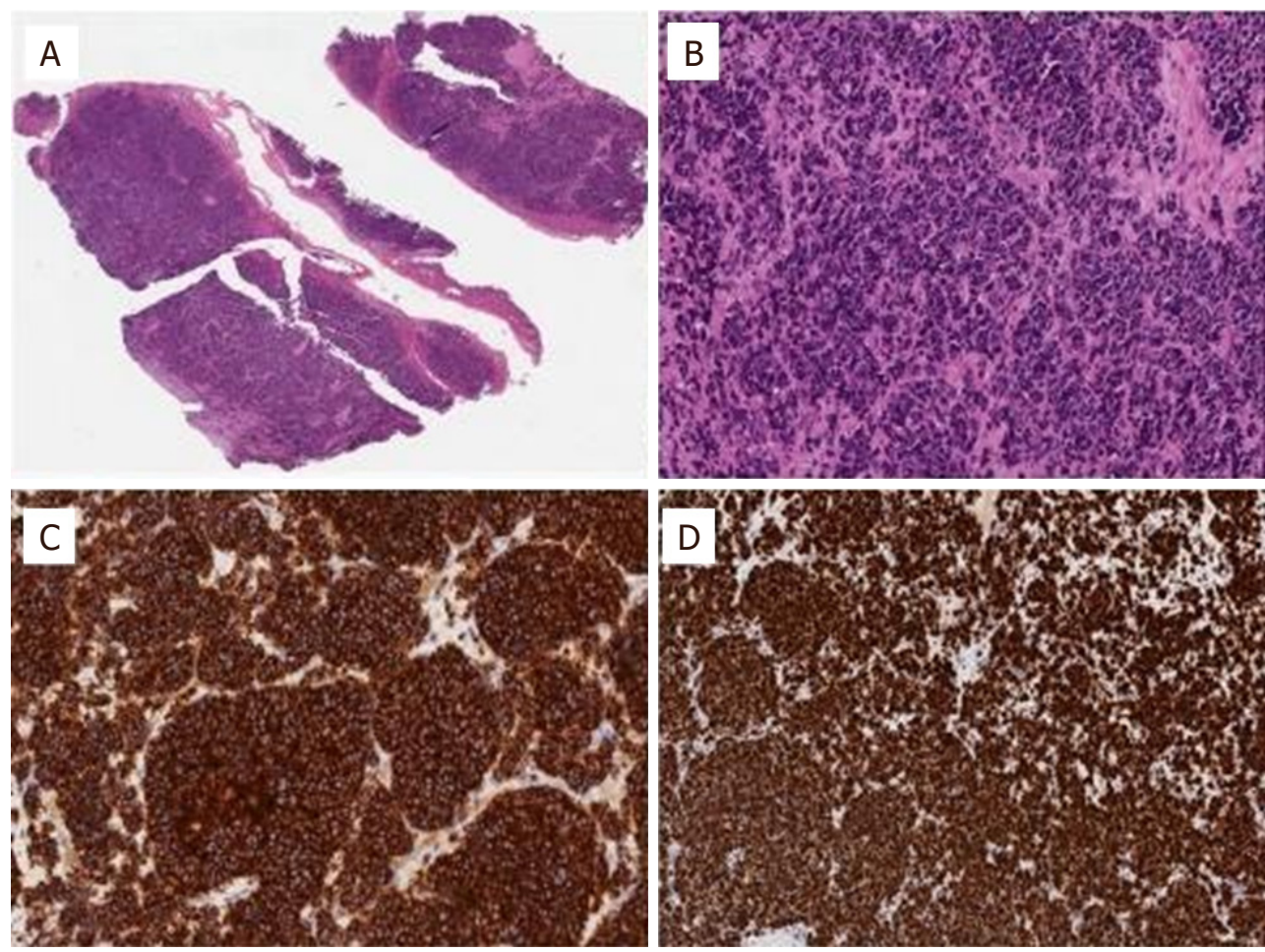

Figure 4. A: Liver metastasis at low magnification (H\&E); B: Liver metastasis at high magnification showing small cell carcinoma (H\&E); C: Liver metastasis showing diffuse positivity for synaptophysin (immunohistochemistry); D: Liver metastasis showing high proliferation rate (Mib1, immunohistochemistry)

Patient was hospitalized at the Surgery Department in our hospital where he underwent colostomy to palliate bowel obstruction and third-segment liver lesion biopsy. The histological examination of the liver showed metastasis of small cell NE carcinoma (Mib1 $=90 \%)$ without prostatic features at immunohistochemistry [Figure 4 and Table 1].

After that, the patient came back to our observation in September 2015 in fair conditions (ECOG-PS $=1$ ), with partial pain control, constipation and mild mental confusion. At physical examination, no neurological impairment was reported.

Laboratory evaluation showed PSA $=26.7 \mathrm{ng} / \mathrm{mL}, \mathrm{NSE}=1238 \mathrm{ng} / \mathrm{mL}$, chromogranin $\mathrm{A}=454 \mathrm{ng} / \mathrm{mL}$, rise of cholestasis values grade 1 according to Common Terminology Criteria for Adverse Events (CTCAE) v4.0 and first occurrence of moderate hyponatremia (125 mEq/L). 
Table 1. Comparison between prostate and liver histology

\begin{tabular}{lll}
\hline & \multicolumn{1}{c}{ Prostate } & \multicolumn{1}{c}{ Liver } \\
\hline Morphology & $\begin{array}{l}\text { Acinar adenocarcinoma with neuroendocrine } \\
\text { differentiation (5\%), Gleason score 5 + 4 =9 } \\
\text { (grade group 5) }\end{array}$ & $\begin{array}{l}\text { Small cell neuroendocrine } \\
\text { carcinoma }\end{array}$ \\
PSMA & Diffuse positivity & Negative \\
Synaptophysin & Focal & Diffuse \\
Mib1 & $50 \%$ & $90 \%$ \\
\hline
\end{tabular}

PSMA: prostate specific membrane antigen

After Endocrinological Consultant, we performed the following evaluations: glucose $=96 \mathrm{mg} / \mathrm{dL}$, serum creatinine $=0.35 \mathrm{mg} / \mathrm{dL}$, blood urea nitrogen $=9.8 \mathrm{mg} / \mathrm{dL}$, plasma osmolality $=259 \mathrm{mOsm} / \mathrm{kg}$, urinary osmolality $=322 \mathrm{mOsm} / \mathrm{kg}$, urinary calcium $=2.4 \mathrm{mg} / \mathrm{dL}$, urinary sodium $=115 \mathrm{mEq} / \mathrm{L}$, urinary potassium $=5.3 \mathrm{mEq} / \mathrm{L}, \mathrm{TSH}=1.1 \mathrm{mcU} / \mathrm{mL}, \mathrm{ACTH}=14 \mathrm{pg} / \mathrm{mL}$, plasmatic cortisol $=9.9 \mathrm{mcg} / \mathrm{dL}$, venous bicarbonates $=25 \mathrm{mmol} / \mathrm{L}$. Therefore, considering also euvolemic status and no concomitant use of diuretics, we diagnosed SIAD and started treatment with Tolvaptan $15 \mathrm{mg} / \mathrm{die}$ in October 2nd 2015 carefully monitoring plasmatic sodium every six hours. Sodium increase was $<10 \mathrm{mmol} / \mathrm{die}$ up to $\mathrm{Na}^{+}=$ $133 \mathrm{mEq} / \mathrm{L}$ and the patient continued progressively to reduce Tolvaptan dosage till a maintenance dose of $3.75 \mathrm{mg} / \mathrm{die}$, monitoring plasmatic sodium daily.

Considering last histological examination and the clinical benefit with vaptan, after evaluation, the patient started a second-line chemotherapy with Cisplatin $80 \mathrm{mg} / \mathrm{m}^{2}$ i.v. day 1 and Etoposide $100 \mathrm{mg} / \mathrm{m}^{2}$ i.v. days 1-3 every three weeks. After three cycles of chemotherapy, the patient experienced grade 3 anemia, grade 2 thrombocytopenia, grade 4 leucopenia and grade 4 neutropenia, requiring blood transfusion and administration of granulocyte growth factor and antibiotics. No other toxicities were reported. Patient underwent a fourth cycle with reduced doses. PSA value was stable, while NE tumor markers increased.

In December 2015, patient experienced bone disease progression at CT scan. A month later, he died due to liver failure.

\section{DISCUSSION}

Hyponatremia is defined as serum sodium concentration $\left(\mathrm{Na}^{+}\right)$lower than $135 \mathrm{mmol} / \mathrm{L}^{[8,9]}$ and it is one of the most common electrolyte disorders occurring in cancer patients with an estimated incidence between $5 \%$ and $20 \%{ }^{[10,11]}$. The most frequent causes include SIAD, due in most cases to ectopic production of antidiuretic hormone, extracellular fluid depletion or renal toxicity of chemotherapy, especially platinum-based ${ }^{[5]}$.

The main diagnostic criteria for SIAD are: euvolemic status, reduced plasma osmolality $<275 \mathrm{mOsm} / \mathrm{kg}$, increased urine osmolality $>100 \mathrm{mOsm} / \mathrm{kg}$, increased urinary sodium $>30 \mathrm{mEq} / \mathrm{L}$, normal kidney, thyroid and adrenal function. Additional diagnostic criteria are: no use of diuretics, reduced blood uric acid $<4 \mathrm{mg} / \mathrm{dL}$, reduced blood urea nitrogen $(\mathrm{BUN})<10 \mathrm{mg} / \mathrm{dL}$, increased sodium renal excretion fraction $>1 \%$ and increased urea excretion fraction $>55 \%{ }^{[6]}$.

Correct management of hyponatremia represents an important issue for cancer patients considering its well-demonstrated role in increasing mortality, costs and length of hospitalization ${ }^{[12-14]}$. Treatment depends on underlying causes of hyponatremia but also on severity and time of onset. In the context of SIAD, vaptans represent a relevant therapeutic option for mild-moderate reduction ${ }^{[15]}$. 
Literature review revealed that most PAC-associated SIAD cases are high grade and high stage adenocarcinoma. Actually, SIAD can be linked to neuroendocrine evolution at disease progression. Pure small-cell carcinoma of the prostate is extremely rare, accounting for $<0.5 \%$ of all cases ${ }^{[16]}$. About $50 \%$ of small cell carcinomas (SCC) have a history of usual PAC. Frequently, at initial diagnosis SCC are seen admixed with adenocarcinoma of the prostate ${ }^{[17]}$. In these cases, Gleason score is assigned only to the conventional adenocarcinoma component. According to the SEER database, the presence of concomitant high-grade PAC is an independent predictor of poorer cancer-specific mortality ${ }^{[18]}$.

Recent data on in vitro and in vivo studies related to the molecular mechanism of $\mathrm{NE}$ transdifferentiation of PCa cells suggest that PCa cells undergo a transdifferentiation process to become NE-like cells, acquiring NE phenotype and NE markers. Common molecular alterations between PAC and SCC components of mixed prostate tumors under conditions of androgen deprivation sustain the hypothesis that small cell carcinoma represents a transdifferentiation from PAC ${ }^{[19]}$. The model of divergent-differentiation consider instead the hypothesis of a common stem cell progenitor that can differentiate into both adenocarcinoma and SCC. According to this model, hormonal therapy determinates a selective pressure resulting in development of SCC from a subpopulation of hormone-independent cells and consequently inducing hormonal resistance ${ }^{[20]}$. The more aggressive behavior compared with conventional PAC is due to expression of genes involved in cellular proliferation, mitosis, neuroendocrine differentiation, along with downregulation of genes encoding cell adhesion molecules ${ }^{[2]}$. This biological molecular phenotype is the reason behind the high proliferation rate, the rapid spreading and the great tendency to metastasize. Further preclinical results, deriving mostly from SCLC cell lines, seem to confirm the relation between hyponatremia, directly or through vasopressin receptors and cell proliferation, resistance to programmed cell death, angiogenesis and metastatization. Mitogen-activated protein kinase (MAPK) pathway is the main intracellular signalling which leads to tumoral growth and spreading ${ }^{[22,23]}$. SIAD onset may guide physicians to perform a tumor biopsy in order to obtain a new morphological and immunohistochemical characterization ${ }^{[24]}$.

Neuroendocrine prostatic cancer is generally managed by chemotherapy regimens similar to those for SCLC. Prognosis is poor with a median survival of 7 months.

It is still unclear how SIAD arises from prostatic carcinoma with neuroendocrine differentiation but it may involve an ectopic production of $\mathrm{ADH}$ from carcinoma cells, as detected immunohistochemically in the tumor tissue ${ }^{[25]}$.

In our case-report, SIAD appeared at progression of disease, with metastatic spread to the liver. In particular a dedifferentiation of cancer cells was reported, which lost prostatic markers to acquire fully neuroendocrine characteristics. Only focal neuroendocrine prostatic markers were reported in the primary prostatic cancer [Figure 1], while liver metastasis presented neuroendocrine carcinoma [Figure 4]. Our case supports the hypothesis that histological evolution to neuroendocrine features accompanies to metastatic spread and often with paraneoplastic syndrome as SIAD.

\section{DECLARATIONS}

\section{Authors' contributions}

Conception and design of the study and performed data analysis and interpretation: Fiordoliva I, Marcantognini G, Rinaldi S

Performed data acquisition, as well as provided administrative, technical and material support: Cimadamore A, Montironi R, Berardi R 


\section{Availability of data and materials}

Patient's data were extracted from medical record. All information are available from the corresponding author upon request.

\section{Financial support and sponsorship}

This research received no specific grant from any funding agency.

\section{Conflicts of interest}

Rossana Berardi has received consulting fees or honoraria from Otsuka (Otsuka Pharmaceutical Co., Japan). The other authors declared no potential conflicts of interest with respect to the research, authorship, and/or publication of this article.

\section{Ethical approval and consent to participate}

Written informed consent for diagnostic and therapeutic procedures was obtained.

\section{Consent for publication}

Not applicable.

\section{Copyright}

(c) The Author(s) 2019.

\section{REFERENCES}

1. Torre LA, Bray F, Siegel RL, Ferlay J, Lortet-Tieulent J, et al. Global cancer statistics, 2012. CA Cancer J Clin 2015;65:87-108.

2. Humphrey PA, Moch H, Cubilla AL, Ulbright TM, Reuter VE. The 2016 WHO Classification of Tumours of the Urinary System and Male Genital Organs-Part B: Prostate and Bladder Tumours. Eur Urol 2016;70:106-19.

3. Hugosson J, Carlsson S, Aus G, Bergdahl S, Khatami A, et al. Mortality results from the Göteborg randomised populationbased prostate-cancer screening trial. Lancet Oncol 2010;11:725-32.

4. Hong MK, Kong J, Namdarian B, Longano A, Grummet J, et al. Paraneoplastic syndromes in prostate cancer. Nat Rev Urol 2010;7:681-92.

5. Castillo JJ, Vincent M, Justice E. Diagnosis and management of hyponatremia in cancer patients. Oncologist 2012;17:756-65.

6. Grohé C, Berardi R, Runkle I. SIADH: differential diagnosis and clinical management. Endocrine 2017;55:311-9.

7. Petereit $\mathrm{C}$, Zaba O, Teber I, Lüders H, Grohé C. A rapid and efficient way tomanage hyponatremia in patients with SIADH and small cell lung cancer: treatment with tolvaptan. BMC Pulm Med 2013;13:55.

8. Palmer BF, Gates JR, Lader M. Causes and management of hyponatremia. Ann Pharmacother 2003;37:1694-702.

9. Ghali JK. Mechanisms, risks, and new treatment options for hyponatremia. Cardiology 2008;111:147-57.

10. Berghmans T, Paesmans M, Body JJ. A prospective study on hyponatraemia in medical cancer patients: epidemiology, etiology and differential diagnosis. Support Care Cancer 2000;8:192-7.

11. Waikar SS, Mount DB, Curhan GC. Mortality after hospitalization with mild, moderate, and severe hyponatremia. Am J Med 2009;122:857-65.

12. Corona G, Giuliani C, Parenti G, Norello D, Verbalis JG, et al. Moderate hyponatremia is associated with increased risk of mortality: evidence from a meta-analysis. PLoS One 2013;8:e80451.

13. Boscoe A, Paramore C, Verbalis JG. Cost of illness of hyponatremia in the United States. Cost Eff Resour Alloc 2006;4:10.

14. Berardi R, Caramanti M, Castagnani M, Guglielmi S, Marcucci F, et al. Hyponatremia is a predictor of hospital length and cost of stay and outcome in cancer patients. Support Care Cancer 2015;23:3095-101.

15. Grohé C, Berardi R, Burst V. Hyponatraemia--SIADH in lung cancer diagnostic and treatment algorithms. Crit Rev Oncol Hematol 2015;96:1-8.

16. Hu J, He T, Jin L, Li Y, Zhao Y, et al. Pure small-cell carcinoma of the prostate presenting with increasing prostate-specific antigen levels: A case report and review of the literature. Mol Clin Oncol 2018;9:197-200.

17. Wang W, Epstein JI. Small cell carcinoma of the prostate. A morphologic and immunohistochemical study of 95 cases. Am J Surg Pathol 2008; 32:65-71.

18. Deorah S, Rao MB, Raman R, Gaitonde K, Donovan JF. Survival of patients with small cell carcinoma of the prostate during 1973-2003: a population-based study. BJU Int 2012;109:824-30.

19. Yuan TC, Veeramani S, Lin MF. Neuroendocrine-like prostate cancer cells: neuroendocrine transdifferentiation of prostate adenocarcinoma cells. Endocr Relat Cancer 2007;14:531-47.

20. Miyoshi Y, Uemura H, Kitami K, Satomi Y, Kubota Y, et al. Neuroendocrine differentiated small cell carcinoma presenting as 
recurrent prostate cancer after androgen deprivation therapy. BJU Int 2001;88:982-3.

21. Lapuk AV, Wu C, Wyatt AW, McPherson A, McConeghy BJ, et al. From sequence to molecular pathology, and a mechanism driving the neuroendocrine phenotype in prostate cancer. J Pathol 2012;227:286-97.

22. Péqueux C, Keegan BP, Hagelstein MT, Geenen V, Legros JJ, et al. Oxytocin- and vasopressin-induced growth of human smallcell lung cancer is mediated by the mitogen-activated protein kinase pathway. Endocr Relat Cancer 2004;11:871-85.

23. North WG, Cole B, Akerman B, Pang RH. Growth Impairment of Small-Cell Cancer by Targeting Pro-Vasopressin with MAG1 Antibody. Front Oncol 2014;11:4-16.

24. Miretti VS, Ávila RA, Sierra JT, García JJ, Laborié MV. Prostate carcinoma and syndrome of inappropriate antidiuretic hormone secretion. Medicina (B Aires) 2018;78:290-3. (in Spanish).

25. Kawai S, Hiroshima K, Tsukamoto Y, Tobe T, Suzuki H, et al. Small cell carcinoma of the prostate expressing prostate-specific antigen and showing syndrome of inappropriate secretion of antidiuretic hormone: an autopsy case report. Pathol Int 2003 Dec;53:892-6. 